Article

\title{
Does Functional Lateralization in Birds Have any Implications for Their Welfare?
}

\author{
Lesley J. Rogers * (1) and Gisela Kaplan \\ School of Science and Technology, University of New England, Armidale, NSW 2351, Australia \\ * Correspondence: lrogers@une.edu.au
}

Received: 29 July 2019; Accepted: 9 August 2019; Published: 13 August 2019

\begin{abstract}
We know a good deal about brain lateralization in birds and a good deal about animal welfare, but relatively little about whether there is a noteworthy relationship between avian welfare and brain lateralization. In birds, the left hemisphere is specialised to categorise stimuli and to discriminate preferred categories from distracting stimuli (e.g., food from an array of inedible objects), whereas the right hemisphere responds to small differences between stimuli, controls social behaviour, detects predators and controls attack, fear and escape responses. In this paper, we concentrate on visual lateralization and the effect of light exposure of the avian embryo on the development of lateralization, and we consider its role in the welfare of birds after hatching. Findings suggest that light-exposure during incubation has a general positive effect on post-hatching behaviour, likely because it facilitates control of behaviour by the left hemisphere, which can suppress fear and other distress behaviour controlled by the right hemisphere. In this context, particular attention needs to be paid to the influence of corticosterone, a stress hormone, on lateralization. Welfare of animals in captivity, as is well known, has two cornerstones: enrichment and reduction of stress. What is less well-known is the link between the influence of experience on brain lateralization and its consequent positive or negative outcomes on behaviour. We conclude that the welfare of birds may be diminished by failure to expose the developing embryos to light but we also recognise that more research on the association between lateralization and welfare is needed.
\end{abstract}

Keywords: lateralization; birds; visual behaviour; light exposure; development; corticosterone; welfare

\section{Introduction}

Lateralized brain function is widespread amongst vertebrate species, ranging from the earliest vertebrates to lateralization of the human brain [1-3]. It is even manifested in invertebrate species [4], and has mostly been studied in bees $[5,6]$. In some studies of vertebrate lateralization, it has been shown that strength of lateralization varies between individuals and this has consequences for cognitive performance [2] and possible ramifications for behavioural differences between individuals. Despite this variation, within a species or group the majority of individuals are Lateralized in the same direction (i.e., Lateralized at the population-level).

In this paper, we consider first the evidence for lateralization of visual behaviour in birds, summarising the evidence for its presence in a range of avian species. Then, we discuss whether knowledge of lateralization has any relevance to husbandry and welfare of avian species. We focus on lateralization of visual perception, processing and response for two reasons. First, most research on lateralization in birds has been on visual behaviour. Secondly, the strength of visual lateralization can be manipulated by exposing the developing embryos to light or incubating them in darkness. As we elaborate, influencing the strength of lateralization is thought to be a way of improving welfare after hatching. 


\section{Studies of Lateralization Conducted in Laboratory Settings}

The first evidence that the left and right hemispheres of the avian brain have different functional roles came from studying the control of song of the chaffinch, Fringilla coelebs $[7,8]$; namely, that the left hemisphere (via the left tracheosyringealis nerve) controls the production of song and that equivalent regions in the right hemisphere have no such function. This discovery was followed by similar evidence in other songbird species, including two species of sparrow, Zonotrichia spp., and the canary, Serinus canarius [9]. Not surprisingly, these discoveries began an active field of research on lateralization of bird song at the behavioural, anatomical and cellular levels (see [10] for a recent study) and parallels have been drawn between acquisition of bird song and of human speech [11]. However, we mention this only in passing since, in this paper, we focus on lateralization of visual perception and response to visual stimuli.

In 1979, Lateralized processing of visual information and control of visual behaviour was discovered in the domestic chick, Gallus gallus domesticus [12]. Interference with function of the left hemisphere was found to impair the chick's ability to learn to discriminate grains of chick mash from a background of small pebbles. The same interference of the right hemisphere had no effect on this performance. In contrast, the right hemisphere was found to be involved in response to stimuli eliciting either attack or copulation, both of which are normally inhibited by the left hemisphere [13].

These studies provided the first evidence of brain asymmetry in non-human species that, in time, became accepted as a general characteristic of vertebrates, certainly not unique to humans as had been thought before. Importantly, asymmetries of visually guided behaviour could be shown simply by testing birds monocularly, since each eye sends most of its inputs to its contralateral hemisphere [14,15]: occlusion of the right eye, and hence use of the left eye, impairs the chick's ability to discriminate grain from pebbles. It also leads to elevated levels of copulation and attack [16]. Preferential use of the left eye before lodging an attack peck at another chick has also be shown in chicks tested binocularly (without eye patches): by videotaping pairs of chicks from overhead, Vallortigara et al. [17] demonstrated a bias for the attacker to view the chick about to be pecked with the lateral field of its left eye.

Revealing lateralization by testing birds monocularly has been a method employed widely in the laboratory and also in wild birds (see later). An important study compared the approach of chicks tested monocularly with a choice between their imprinted stimulus and another, slightly modified stimulus. When using their left eye, chicks responded to small changes in the imprinted stimulus. When using their right eye, they detected and responded only to large changes in the imprinted stimulus [18]. These results led to the conclusion that the right-eye-system (viz., right eye and left hemisphere) categorises stimuli and thus responds only to larger, categorical differences between stimuli, whereas the left-eye-system (left eye and right hemisphere) detects and responds to even small differences, clearly identifying the left-eye-system's superiority in responding to novel stimuli. It is this division of roles between the eyes/hemispheres that explains why chicks recognise familiar from unfamiliar chicks when they can see them with their left eye but not when they can see them with their right eye [19]. In keeping with this, the left-eye-system is specialised for social behaviour. It deals with the information needed to form dominance hierarchies $[20,21]$ and for social learning by observation [22]. The left-eye-system also detects and responds to predators [23-25] and it expresses fear or distress, as judged by elevated distress calling [23].

The domestic chick has become a model for study of lateralization in a broad range of contexts. Since the initial studies were conducted, research in Giorgio Vallortigara's laboratory has shown that chicks prefer to monitor biological motion using their left eye [26]. This finding is consistent with the left-eye-system's superiority in responding to a predator, as mentioned above, and its role in social behaviour.

Further research in Richard Andrew's laboratory revealed differential processing of memory formation in the left and right hemispheres of the chick [27,28]. Additionally, Rogers investigated the development of lateralization, finding an essential role for light exposure during embryonic development $[13,29]$. The latter is discussed more fully below. 
The first report of visual lateralization in a species other than Gallus gallus came from Güntürkün's research group. Güntürkün and Kesch [30] demonstrated the presence of lateralization in the pigeon, Columba livia, by testing birds monocularly. Similar to the finding in chicks, pigeons tested using their right, but not their left, eye could discriminate grains of food from pebbles. Using the right-eye-system pigeons can also categorise and remember a large number of visual patterns [31]. Once they have categorised certain stimuli (images with a human versus without a human), then using their left-eye-system they are more responsive to scrambling of the images than they are when they are using the right-eye-system [32]. In other words, the left eye system is responsive to small differences between stimuli, whereas the right eye system attends to categorical/large differences. This result is in keeping with the pattern of lateralization found in chicks.

More recently, pigeons were shown to learn a colour discrimination task faster when using the right-eye-system and they also responded faster when they saw the rewarded stimulus [33]. Additionally, more excited neurones were recorded in the left than in the right hemisphere. These results, together with more detailed electrophysiological measurements in the left and right hemispheres, allowed Xiao and Güntürkün [33] to demonstrate that the left hemisphere can delay timing of neural activity in the right hemisphere via commissural interactions between the hemispheres. Expressed differently, the left hemisphere (right-eye-system) can assume dominance in controlling behaviour in this discrimination task. It does so by modulating the visual inputs to higher brain regions [34]. In other words, during learning of that visual discrimination task, the right-eye-system assumes dominance and, by deduction, the left-eye-system is less influenced by learning and remains open to detecting novelty and small changes in perceived stimuli.

Both chickens and pigeons show a left-side bias when pecking at an array of grain, indicating left-eye-system (right hemisphere) control of visuo-spatial attention [35]. The following studies support this conclusion. Homing pigeons tested monocularly follow their route home with more fidelity when they use their left-eye-system, again demonstrating the role of the right hemisphere in spatial performance [36]. In a spatial task, chicks were shown to attend to global spatial cues when using the left-eye-system and to proximal geometric cues when using their right-eye-system [37].

No other avian species has received the same amount of research interest as have chickens and pigeons but some laboratory studies have investigated lateralization in a species of crow, Corvus monedula, and in the zebra finch, Taeniopygia guttata. Clayton and Krebs [38] reported that crows tested in the laboratory have a right eye preference for attending to object-specific cues and a left eye preference for attending to spatial cues but, to our knowledge, lateralization in this species has not been pursued further. More attention has been paid to lateralization in the zebra finch. Firstly, zebra finches display the same ability as chicks to discriminate grain from pebbles only when they use their right, and not their left, eye [39]. Secondly, zebra finches have been reported to show a preference to use the left eye when looking at a predator, as chicks also do [40]. Interestingly, Workman and Andrew [41] reported that, during courtship, males of this species prefer to approach females so that they view them with their right eye. Although this result was contested by Ten Cate et al. [42], other evidence supported preferential right-eye use during courtship $[43,44]$. The preference shown by zebra finches to use the right eye when courting a female would, at first sight, appear to contradict specialization of the left-eye-system for control of copulation, as found in the chick. However, as we have argued previously [40], courtship involves different control by the forebrain than does copulation. In fact, courtship behaviour requires inhibiting the actual copulation response. Since copulation is controlled by the right hemisphere, inhibition of the right hemisphere by the left hemisphere would be needed in order for the bird to continue courting without actually attempting to copulate. This inhibition could be achieved only via use of the right-eye-system (left hemisphere) [45]. Courtship also requires discrimination choice and, as found in food searching tests, this is a specialisation of the right-eye-system. In fact, zebra finches using their right eye choose between females with different colouration of the beak. A preference to court higher quality females with orange, versus grey, beaks was shown when the right-eye-system was used: males using their left-eye-system courted females 
irrespective of their beak colour [44]. Colour-polymorphic Gouldian finches, Erythrura gouldiae, display three completely discrete but naturally co-occurring morphs; with head markings in yellow, red or black. Females choose partners using UV reflection and other markers, whereas males do so by head colour [46]. Even though redheads are dominant and may be available, black-headed males courted black-headed females by preference and used the right-eye-system to do so [47]. These are examples of categorical choices made using the right eye and left hemisphere.

Lateralization in quail, Coturnix spp., has also been reported. Valenti et al. [48] reported that young domestic quail, as do chickens and pigeons, discriminate between grain and pebbles better when they use their right eye than when they use their left eye [48]. Additionally, as in chicks, adult Japanese quail show a left-eye-system superiority in visually guided sexual behaviour $[49,50]$.

From these studies, a general pattern of lateralization has become evident, summarised in Table 1. The left hemisphere is specialised to categorise objects and choose between types of conspecifics. It discriminates between categories and memorises patterns. It is the hemisphere used when attention is focussed on the task being performed and under relatively relaxed conditions [51]. The right hemisphere is used in emotionally charged situations, including detection of predators, in agonistic interactions and copulation and in escape responses [51]. This leads us to ask whether the same pattern is seen in wild-living avian species.

Table 1. Summary of population lateralization found in avian species in the wild.

\begin{tabular}{ll}
\hline Left Hemisphere (Right Eye) & Right Hemisphere (Left Eye) \\
\hline Juncos look outward while feeding & Tree sparrows look outward while feeding \\
\hline Caspian terns hold fish with head to right & Kookaburras look down at ground \\
\hline Stilts more successful in prey capture & Coots and swan geese look at ground while foraging \\
\hline Magpies in low arousal approach & Stilts look at female when courting before copulation \\
Magpies in Fiji to scan for predator & $\begin{array}{l}\text { Magpies high arousal inspection of predator, } \\
\text { scanning for and detecting an aerial predator, and } \\
\text { before fleeing }\end{array}$ \\
\hline Sandpipers to scan for predators & Magellanic penguins in aggression \\
\hline Sage-grouse to view female when courting & $\begin{array}{l}\text { Sage-grouse in aggression } \\
\text { Sage-grouse in copulation }\end{array}$ \\
\hline
\end{tabular}

\section{Evidence of Lateralization in Field Studies}

To our knowledge, lateralization in birds tested in their natural environment was first reported by Franklin and Lima [52]. They observed two species of sparrow as they fed alongside a wall and they recorded which eye faced away from the wall. The authors assumed that the birds positioned themselves next to the wall so that they could look for predators with their eye not next to the wall. Dark-eyed juncos, Junco hyemalis, they found, had a preference to look outward using their right eye. American tree sparrows, Spizella arborea, by contrast, showed a preference to look outwards using the left eye. This opposite eye preference between the species remains unexplained since it was not possible to know whether both species were, indeed, scanning for predators or, possibly in the case of the juncos, using the right eye to look out for alternative items of food.

Field observations of the eye used by kookaburras, Dacelo gigas, to scan the ground when perched at a height, on electrical wires, found a strong left-eye preference [53]. In this case, choice of the left-eye-system could indicate attention to spatial location of potential prey.

A field study of Lateralized behaviour in black-winged stilts, Himantopus himantopus, scored lateral biases in two types of behaviour, feeding and sexual behaviour [54]. The stilts were more successful in capturing prey when they looked with their right, monocular visual field before pecking. Females viewed by males using their left, monocular visual field caused the male to perform more preening of their breast and wings and dipping their beaks in water with shaking the head, which 
the researchers say are components of both courtship and copulation. Given our discussion above, it would be interesting to see whether courtship behaviour could be separated from copulatory behaviour. Nevertheless, these complementary specializations of the left and right eye systems match those found in chicks (above) and, incidentally, they also match those found in toads [55].

More recently, a number of Lateralized behaviours have been found in Australian magpies, Gymnorhina tibicen in foraging [56] and in responses to predators [57]. The responses of the magpies to a taxidermic specimen of one of their nest predators, a monitor lizard, were scored in the natural environment [57]. A significant and strong left monocular field preference was recorded for viewing the monitor lizard prior to withdrawing from it and also for high alert inspection of the monitor lizard, as well as for looking at it while circling around it. Prior to approaching the monitor lizard, which occurred in some cases in a state of low arousal, a preference to view it with the right monocular visual field was found. In another study, magpies were also found to look with their left eye before flying away from a human approaching the bird from behind [58]. A notable finding in both studies was a preference to use the left-eye-system when arousal levels were high and the magpie was likely to flee or to stay at a distance from the predator. Use of the right-eye-system occurred during low arousal approach to examine the monitor lizard.

Wild magpies also use the left-eye-system to scan overhead to detect a predator, a raptor in this case, as shown by assessing the eye used to look upwards when they heard their "eagle" alarm call; we found an $84 \%$ preference to use the left eye $[59,60]$. Interestingly, similar tests applied to the same species introduced to Fiji several generations ago found a right-eye preference for scanning overhead [60], which we attributed to the fact that the raptors in Fiji are concealed in overhead trees. This contrasted with the conditions in which the birds were tested in Australia, where no trees were overhead and raptors would have been flying and clearly visible in the sky. When predators must be distinguished against a complex background, as in Fiji, the right-eye-system is better equipped for detecting them.

The above might, possibly, explain the right-eye-system preference found by Beauchamp [61], who scored sandpipers, Calidris pusilla, feeding on a mudflat and watching out for falcons hiding in the trees bordering the mudflat. The birds oriented with their right eye to the trees were more successful in foraging than were those using their other eye system. However, more species need to be tested for eye preference while foraging before any conclusions can be drawn. Randler [62] reported a left-eye preference to look at the ground while foraging in coots, Fulica atra, and swan geese, Anser cygnoides, and no preference in grey-lag geese, Anser anser. While the coots and swan geese might have been using their right-eye-system to scan for predators, as the researchers suggested, they tend to scan for predators by interrupting foraging and lifting their head up to scan the surroundings. We suggest that, as in kookaburras, they may choose the left eye during foraging because they need to rely on spatial information, not visual discrimination. In fact, the same may be the case in sandpipers. Conditions of testing in the wild cannot always be as controlled as they are in the laboratory and this can make it difficult to interpret the results.

Although it is not known whether handling of prey while feeding chicks is purely tactile or involves visual inputs, it is worth mentioning a study of Caspian terns, Hydroprogne caspia, which found a side preference for holding fish in the bill [63]. Successful feeding of the chicks occurred more often when the adult bird held the fish crosswise in its bill with the fish's head to the right side of the bird. Any head-to-left holding was switched to head-to-right before feeding. It is, of course, uncertain whether this reflects a right-eye preference, but the head of the prey would be the most attractive part of its body and that is in the visual field of the right eye. Since the chick swallows the fish head-first, the adult bird must turn its head to the left side in order to transfer the fish head-first into the beak of the chick. This suggests that the orientation preference is more likely to be a lateralization of the adult rather than of the chick. However, it does depend on the age of the chick, since the side preference is significant only for the first one- or two-weeks post-hatching. 
A recent field study of Magellanic penguins, Spheniscus magellanicus, has found asymmetry of injuries caused by intraspecific fighting [64]. More injuries were found on the right side of penguins that had been attacked. Since the penguins were most often attacked from a position in which they stand side-by-side facing the same way, the authors deduced that the attacking penguins have a preference to use their left eye, as reported in chicks (see above) and other species (toads [65]; horses [66]).

Lateralization of aggressive behaviour has also been reported to be left-eye biased in sage-grouse, Centrocercus urophasianus [67]. During courtship, males of this species showed a preference to view the female with the right monocular visual field. When the female was viewed using the frontal binocular field, a left-side bias was found but only in males that mated successfully during the mating season: no bias was present for males that were not successful in mating. These data add to the evidence of courtship depending on right-eye (left-hemisphere) use, whereas actual copulation behaviour is under left-eye (right hemisphere) control.

The results of these studies reporting population-level lateralization in wild birds are summarised in Table 1. Despite apparent discrepancies, in a general sense, the lateralization found in these studies of wild birds seems to fit the pattern determined in laboratory tests (Table 2). In fact, the same pattern of lateralization is seen in a wide range of vertebrates from fish to humans (summarised in $[1,68]$ ).

Table 2. Functions controlled by the left and right hemispheres.

\begin{tabular}{|c|c|}
\hline Left Hemisphere (Right Eye) & Right Hemisphere (Left Eye) \\
\hline $\begin{array}{l}\text { Attends to categories of stimuli-notices only large } \\
\text { differences between stimuli } \\
\text { (chick, pigeon, zebra finch, quail, stilt*) }\end{array}$ & $\begin{array}{l}\text { Detects novelty-notices small differences between } \\
\text { stimuli } \\
\text { (chick, pigeon) }\end{array}$ \\
\hline $\begin{array}{l}\text { Discrimination of objects (food) from distracting } \\
\text { stimuli (pebbles) (chick, pigeon) }\end{array}$ & Social recognition and behaviour (chick) \\
\hline Colour discrimination (pigeon) & Response to biological motion (chick) \\
\hline Proximal spatial attention (chick, crow) & $\begin{array}{l}\text { Global spatial attention (chick, pigeon, crow, } \\
\text { kookaburra*) }^{*}\end{array}$ \\
\hline $\begin{array}{l}\text { Sexual choice/courtship (zebra finch, Gouldian finch, } \\
\text { sage-grouse }^{*} \text { ) }\end{array}$ & Copulation (chick, quail, stilt* ${ }^{*}$ sage-grouse ${ }^{*}$ ) \\
\hline Approach to examine (magpie $\left.{ }^{*}\right)$ & Withdraw and escape (magpie*) \\
\hline \multirow{3}{*}{$\begin{array}{l}\text { Unclear function } \\
\text { (junco* }^{*} \text {, sandpiper*, } \text { coot }^{*} \text {, swan goose }{ }^{*}, \\
\text { starling }{ }^{*} \text { - - see text }\end{array}$} & Attack/aggression (chick, penguin*, sage-grouse*) \\
\hline & $\begin{array}{l}\text { Attention to predators (chick, zebra finch, tree } \\
\text { sparrow }^{*}, \text { magpie }^{*} \text { ) }\end{array}$ \\
\hline & Fear and distress (chick, magpie*) \\
\hline
\end{tabular}

Functions performed by using the left hemisphere (right eye) and by using the right hemisphere (left eye). In brackets are the avian species for which the evidence is available. Asterisks indicate those species of wild birds tested in their natural habitat.

Apart from lateralization at the population level, it can be important to study lateralization at the individual level. Individual lateralization has an advantage in cognitive decisions, as shown recently in American robins, Turdus migratorius [69]. Nests of this species are often parasitised by brown-headed cowbirds, Molothrus ater, that lay their eggs in the robins' nests, but these eggs are often rejected by the host bird. By placing model eggs in the robins' nests the researchers were able to show that the robins viewed them monocularly, some with their left eye and others with their right eye (i.e., individual but not population lateralization) and the stronger the lateralization, the more successful the birds were in rejecting the model eggs. In this case, lateralization confers an advantage on the individual bird but there has been no evolutionary selection or developmental pressure to align the direction of lateralization within the population. 


\section{General Pattern of Avian Lateralization and the Advantage of Being Lateralized}

The fact that lateralization at the population-level is common in avian species, as well as other vertebrates and invertebrates [45], leads one to deduce that it must be advantageous despite the fact that side biases in perception and behaviour would seem to be disadvantageous since food, social companions and predators might be on the animal's left or right side.

Recognising the latter, Vallortigara and Rogers [70] hypothesised that population lateralization, as opposed to lateralization at the individual level, could confer an advantage when one Lateralized individual interacts with another Lateralized individual. The hypothesis therefore predicted that population lateralization would be present in social behaviour and other behaviour performed in a group. There is evidence in support of this hypothesis, however, thus far, it has come only from studies on bees, and by comparing social with non-social species. Highly social honeybees, Apis mellifera, have strong population-level lateralization in antennal responses to certain odours, whereas solitary mason bees, Osmia cornuta, have no such lateralization [71]. The latter species does, however, show population-level lateralization in the rare social interactions in which it does engage: viz., aggressive interactions with conspecifics [72]. Hence, it is in social behaviour that population lateralization occurs.

Whether this evidence applies also to avian species has not yet been tested. Chickens and pigeons, for example, are highly social species, and feeding is one of their social behaviours. A study using pigeons found a positive correlation between strength of visual lateralization and success in finding grain scattered amongst pebbles: the stronger the visual lateralization, the better their performance [73]. Similarly, Magat and Brown [74] found that, in a range of species of parrots, birds with stronger eye biases during feeding were better able to discriminate grain from pebbles. Better ability to find grain amongst a background of similar inedible objects would clearly be an advantage in the natural environment. The researchers found no population laterality in the parrots; however, although parrots feed in aggregated flocks, there is no evidence that the feeding birds are actually engaged in social behaviour while feeding. Laterality needs to be assessed in large groups of each species during social interactions.

We know that chicks with visual lateralization are able to perform two tasks at once, whereas those not so Lateralized find this very difficult or, mostly, impossible to do [75]. The chicks were required to find food grains scattered on a background of pebbles and, at the same time, scan overhead for the presence of a model predator, the silhouette of a bird of prey. Lateralized chicks performed well on both aspects of the task but chicks not Lateralized for either behaviour were unable to discriminate the grain from the pebbles, even though they had no problem in doing this when tested without simultaneous presentation of the predator. The non-Lateralized chicks were also slower than the Lateralized ones in detecting the overhead predator but, once they had seen it, they were greatly disturbed by it and so distracted by it that they were unable to learn to discriminate grain from pebbles. As shown in monocular tests, the Lateralized chicks were able to allocate each aspect of the task to a different hemisphere (left for finding grain and right for response to the predator), but the non-Lateralized chicks were unable to do this [23]. Clearly, the capacity to deal with such dual tasks is of great survival value, demonstrating a compelling function for having a Lateralized brain but lateralization at the individual level would be sufficient for this purpose. Only in social behaviour is there an advantage for population-level lateralization.

\section{Development and the Role of Light}

Exposure to light during in ovo development establishes visual lateralization, as shown in chicks [13] and pigeons [76]. Owing to the orientation of the late stage embryo in the egg, the right eye is positioned next to the egg shell and thus it is exposed to light entering through the shell and membranes. The left eye is occluded by the embryo's body. This asymmetrical posture ensures that light stimulates development of the neural connections from the retina of the right eye and its neural connections. In turn, the asymmetrical stimulation by light leads to enhanced development of regions of the left side of the brain that process visual information. It also stimulates the development 
of visual pathways from the left side of the midbrain to the forebrain [77-79]. After hatching, the right-eye-system of these birds is better in finding grain on a background of pebbles than is the left-eye-system. If eggs are incubated in darkness this lateralization does not develop. Moreover, by occluding the right eye of the embryo on day 19 of incubation and stimulating the left eye with light, the lateralization is reversed [29]. Hence, exposure to light before hatching is crucial to the development of visual lateralization.

The exposure of embryos to light not only enhances development of the right-eye-system in advance of the left-eye-system but also leads to the left hemisphere being able to inhibit the right hemisphere via interhemispheric neural connections [80,81]. Further experiments have shown, in pigeons, that light exposure of the embryo modulates the balance between the hemispheres [82]. Not only does light exposure generate dominance of the left hemisphere for visuomotor control [76] but also it reverses which hemisphere has better interhemispheric access; it shifts it from the right hemisphere to the left hemisphere. Moreover, it shifts dominance for attentional control, measured as pecking choices at an array of stimuli, from the left to the right hemisphere [82]. In other words, light exposure (of the right eye) affects functioning of both hemispheres of the embryo and alters the balance of control by the hemispheres via modulating the interhemispheric interactions. The likely means by which this occurs at cellular level have been discussed by Güntürkün and Ocklenburg [83].

Light exposure of eggs early in incubation can also influence the development of lateralization manifested after hatching [84] although via a different process than does light-exposure just before hatching since it occurs prior to the establishment of eye to brain connections [85]. Chiandetti et al. tested biases in pecking to the left or right side when the birds were presented with an array of grain and they did so by testing chicks hatched from eggs in three groups: one group incubated in the dark, another exposed to light from day 1 to day 3 of incubation, and a third from day 18 until hatching on day 21 [85]. Both conditions of light exposure led to a left-wards bias in pecking, whereas no such asymmetry was present in the chicks incubated in the dark. In another task the chicks had to detour to the left or right side of a barrier in order to reach a food source at the end of a runway. In this test the dark-incubated chicks showed a preference to detour to the left, whereas neither of the light-exposed groups of chicks showed a side bias. Hence, not only does light exposure generate some aspects of visual lateralization but it can also suppress lateralization of other brain functions.

Similar effects of light stimulation of early and late embryos must be limited to certain tasks, because light exposure of embryos prior to day 19 does not generate the lateralization of performance in the pebble-grain discrimination task. This is known because all of the eggs in the experiments discussed above were exposed to light prior to being incubated in the dark, or exposed to light, in the final few days before hatching $[13,29,86]$. This difference would be expected, since the latter is known to be associated with asymmetrical development of the visual pathways, which takes place only in the final few days before hatching.

A recent study by Chiandetti and Vallortigara [87] has teased apart the effects of early versus late exposure of chicks to light during incubation by scoring repeated pecks at gravel as opposed to pecks at grain. They referred to this behaviour as 'perseveration' on distracting targets and found that, when the chicks were tested with no eye occlusion (binocularly), this behaviour was more common in chicks exposed to light during late incubation compared to chicks exposed to light during early incubation, and also compared to chicks incubated in darkness. This separates the behavioural effects of early versus late exposure to light during incubation. Since monocular tests showed that this 'perseveration' occurs more often when the left-eye-system is used than when the right-eye-system is used; the results also showed that, after late but not early exposure to light, there is better interaction between the hemispheres.

These experiments have shown that light plays a critical role in the development of both precocial species (chicks) and altricial species (pigeons). It might, therefore, be important in the consideration of welfare of birds after hatching. 


\section{What Evidence Is there that Functional Lateralization has Implications for the Welfare of Birds?}

Welfare of avian species concerns birds in captivity either as pets or in commercial farms producing eggs or meat for human consumption. The former refers to a wide range of avian species either caught from the wild or bred in captivity as part of the aviculture industry. The latter refers chiefly to domestic fowl, turkeys and ducks bred and raised in factory farms or other farming conditions. In factory farms, the young birds are usually raised in large flocks housed in sheds and they may remain in this situation until slaughter (e.g., broiler chicks) or they are transferred to small cages (e.g., layer chicks). Conventional cages restrict movement and the ability of hens to exhibit natural patterns of behaviour, but they allow higher rates of survival than occurs in birds housed in large sheds or free-ranging in open fields. In open sheds, aggressive behaviour and access to faeces increases overall mortality rates. Stocking density is highest in cage systems and still very high in open-shed systems. Cage systems are devoid of any enrichment and, in practice, so are most open-shed systems, partly because of stock density. We will discuss separately the relevance of lateralization to birds in commercial farming and birds kept as pets.

\subsection{Exposure to Light During Incubation of Birds Raised in Flocks on Commercial Farms}

A number of studies have compared the effects of light exposure during incubation on the behaviour of chicks in groups. First, groups of chicks exposed to light during the last 3 days before hatching (visually Lateralized) were compared to groups of chicks kept in darkness during this period (no visual lateralization). The size of each group was eight chicks [88]. Between days 8 and 16 post-hatching, social hierarchies in these groups were assessed by scoring competition during space-limited access to food in a bowl. Whereas the groups of chicks hatched from eggs incubated in darkness formed flexible social hierarchies, the groups of chicks that had received exposure to light formed stable social hierarchies with the lowest ranking birds rarely being able to access the food and consequently their growth was affected severely. This finding was confirmed by Wichman at al. [89]. It has been argued that dark-incubation may benefit the raising of young chicks in the sense that all birds gain access to food. However, the absence of a stable hierarchy could lead to increased social competition, which could be detrimental if it persists into adulthood.

Whether these differences in social behaviour are a direct result of the presence versus absence of lateralization of visual behaviour was assumed but not proven directly. Nevertheless, lateralization at the population level would permit consistency when one Lateralized individual interacts with another Lateralized individual and therefore, stability of social interactions [70]. In the absence of population-level lateralization (after incubation in the dark), social interactions would be less predictable and conceivably more variable and inconsistent. This may have ramifications for welfare in terms of expressions of aggression, for instance, but more research is required to confirm such a link.

As mentioned previously, clear differences between light-exposed (visually Lateralized) chicks and dark-incubated (not visually Lateralized) are seen when they have to perform two tasks simultaneously: searching for food and detecting a predator overhead [25]. Given that chicks raised naturally or in commercial conditions have to attend to multiple stimuli at the same time, light-induced lateralization is most likely to have a positive effect on welfare.

Further evidence that exposure of chicken eggs to light affects fear and stress responses after hatching has been provided by Archer and Mench [90,91]. Their study of 2014 reported that the hen leaves the nest, thereby exposing the eggs to light, more frequently during the last week of incubation than prior to that time, and she leaves the nest most often on day 19, a key time for light exposure to lead to visual lateralization. They also assessed four conditions of incubation: exposure to light (1) throughout incubation, (2) during the last two weeks of incubation and (3) during the last week of incubation compared to (4) dark incubation. The hatched chicks were assessed for fear responses 3 to 6 weeks after hatching. The tests included time to emerge from the safety of a dark box, latency to right from tonic immobility and vocalisation when isolated. Compared to the dark-incubated chicks, all of 
the light-exposed chicks were less fearful on all of the measures, and the least fearful chicks were those exposed to light throughout incubation. In a subsequent study, Archer and Mench [91] confirmed the role of light exposure in reducing fear responses and recommended 12 hours of light exposure daily throughout incubation to reduce fear and improve welfare of chicks. Even as little as 6 hours of light per day was sufficient to reduce fear on some tests. Whether or not this effect of light on post-hatching behaviour relates directly to the effect of light exposure on the development of lateralization has yet to be determined. However, differences in lateralization are likely to be involved, and Archer and Mench [91] did show effects of the light exposure on lateralization in tests of turning bias.

Contrary to the above potentially positive effects of light exposure in the final stages of incubation, other evidence suggests that this exposure has a negative effect on welfare of young chicks. Riedstra and Groothuis [92] found that exposing eggs to light for the week prior to hatching increased feather pecking after hatching, compared to chicks that had been incubated in the dark. The light-exposed chicks pecked both familiar and unfamiliar chicks, whereas the dark-incubated chicks preferred to peck unfamiliar chicks. The researchers hypothesised that the inability of light-exposed chicks to discriminate between familiar and unfamiliar companions might stem from dominance of the left hemisphere, and hence less access to the right hemisphere's role in discriminating between individuals (discussed above, and see [18]). However, this simple explanation seems to be unlikely, since, as shown in pigeons ([82], discussed above) light exposure enhances interhemispheric communication and, in chicks tested on the dual task [75], light-exposed chicks were able to use both their left and right hemispheres in parallel. In other words, exposure to light before hatching did not prevent the chicks from using their right hemisphere.

Although the feather pecking in the study by Riedstra and Groothuis [92] was gentle and did not cause damage, it can develop into damaging feather pecking later in life. The researchers concluded that in order to improve welfare of poultry, light exposure before hatching should be avoided. This radical suggestion, depriving chicks of normal conditions of development [90], would require a good deal of weighing up the evidence. Any decision about the value of light exposure pre-hatching would need to take many aspects of behaviour into account. In fact, judging from the rather limited collection of evidence so far, exposure of eggs to light during incubation has measurable benefits and is generally positive for welfare of developing chicks, both because it ensures visual lateralization and for several other positive effects on physiology and behaviour of the hatched chicks (e.g., [93]).

\subsection{Experience during Early Post-Hatching Development in Chickens}

Control of behaviour during early development by either the left or right hemisphere changes during development, as shown in chicks. The left hemisphere dominates during the first week of life post-hatching and the right hemisphere assumes control on days 10 and 11 [94]. This switch from the left to right hemisphere coincides with the age at which chicks begin to explore their environment by moving out of sight of the hen [95] and it is coincident with the chicks' ability to use distal spatial information [96]. Furthermore, providing chicks with barriers inside their cage from day 10 to 12 of post-hatching life, and hence permitting them to go out-of-sight of their social companions during the critical period of right hemisphere control, enhances their ability to attend to distal spatial cues [96]. Attention to distal cues allows birds to navigate or move in larger areas without getting lost or distressed. Being able to do this is certainly of benefit to birds raised in larger enclosures, as in the case for poultry housed in large sheds (e.g., broiler poultry housing) or free-ranging chickens. Increased ability to move over larger distances and around obstacles also provides enrichment, which is a key aspect of welfare.

Rearing of chicks in barren cages, as most often occurs in commercial farms, denies this exploratory and important early experience of going out of sight of each other [97]. Most likely, this is detrimental to behaviour later when the chickens are kept in large, commercial flocks, as is the case for laying hens frequently held in large sheds with several levels of food, water and perches. Incidentally, the 
beneficial effect on spatial behaviour provided by experience with barriers occurs regardless of whether the chicks have been exposed to light before hatching or incubated in the dark [97].

\subsection{Stress during Incubation or after Hatching in Chickens}

Corticosterone is the main stress hormone in birds and each eggs laid is known to contain different levels of this hormone depending on stress experienced by the hen while each egg is forming and before it is laid. Variation in corticosterone levels deposited by the mother in the eggs is seen either in the order in which the eggs are laid [98,99] or differences between clutches of eggs [100]. Endogenous secretion of corticosterone by the embryo itself is also possible once the hypothalamic-pituitary-adrenal axis becomes functional, which occurs by day 18 of incubation, 3 to 4 days prior to hatching.

Corticosterone levels affect the development of the embryo, including an effect on visual lateralization. The latter was shown by injecting corticosterone into chicken eggs on day 18 and then assessing lateralization of the visual projections from the thalamus to the forebrain [101]: lateralization did not develop in chicks hatched from the corticosterone-treated eggs despite the fact that they had been exposed to light. Behaviour after hatching of chicks treated with corticosterone on day 18 of incubation differed from that of untreated chicks in several ways: the treated chicks slept less, made more distress vocalisations and, consistent with their absence of visual asymmetry (see above), they were slower to detect an overhead predator (silhouette of a hawk) while searching for food [102]. The same treatment with corticosterone injected after hatching had none of these effects. Hence, stress during the later stages of incubation seems to have some negative effects on behaviour after hatching because it prevents the development of visual lateralization. Further research is needed to be certain of this causal relationship since elevated corticosterone levels in ovo have a number of other effects on physiological and behavioural development (see [103]).

\subsection{Emotion and Eye Use to View a Stimulus}

Hemisphere and hence eye preference before performing a particular behavioural response should be a measure of the emotional state of a bird. Put simply, use of the left-eye-system could be an indication that the bird is likely to either flee or attack, whereas use of the right-eye-system indicates that the bird is relaxed and in control of the situation, as suggested by Leliveld et al. [68] when considering the welfare of farm animals. Since most birds have their eyes positioned to the sides of their head, angle of the head adopted for viewing monocularly is a convenient way of determining which eye-system is being used. However, some species alternate viewing a stimulus first with one eye and then the other. In these species, the eye-system used first to fixate a stimulus (before alternating) indicates the predominant eye-system used (see method used in [40]).

A rather more detailed measure of eye fixation has been conducted by Butler et al. [104]. They looked at eye use in starlings (Sturnus vulgaris) and found that the birds made several fixations of an object using one eye and then shifted to do the same with the other eye. Important to our paper, they found a left-eye preference for looking at three different stimuli. They suggested that the starlings' monocular alternating fixation strategy may facilitate integrating the different types of information gathered by the different portions of each retina. Various avian species are known to have different viewing strategies, depending on the distribution of cells in their retinas [105]. In chickens we know that close objects (20-30 cm in front) are viewed by using the binocular visual field and more distant objects are viewed by using the lateral, monocular visual field [106]. Since chicks usually decide to respond after using the monocular visual field of only one eye, it is relatively easy to determine eye preferences [17,107]. Additionally, since chicks treated with testosterone use their lateral, monocular visual fields less often than do untreated chicks [107], the likely link between lateralization and steroid hormone levels deserves further attention in a range of avian species, particularly since any such connection could be causally associated with stress levels and, hence, welfare. 


\subsection{Relevance of Lateralization to Welfare of Pet Birds in Captivity}

Very little is known about laterality in those species of birds kept commonly as pets, excepting perhaps zebra finches and some breeds of pigeon. Many species of cockatoo, for example, have population-level lateralization to hold food and other objects [108,109]. To our knowledge, only one research group has reported lateralization of visual behaviour in parrots, namely, the eye used to fixate a food object before grasping it [110]. In 16 species tested, there was a correlation between foot preference and eye preference measured in this task. As discussed above, the same researchers found a significant correlation between strength of eye preference and performance on two problem-solving tasks [74], but the sample used in this analysis included eight different species with a few subjects from each species. Needed now are studies of eye preferences limited to single species to assess performance using the left versus the right eye on any of the tasks listed in Table 1 or on tasks that can be compared to these. One study of pet African grey parrots gathered data from the birds' owners and found a larger vocabulary of mimicked human speech in left-footed individuals than in right-footed ones [111]. Surprisingly, this finding has not yet stimulated further research on this topic.

At this time, it is not possible to say much about the role of lateralization in the welfare of pet birds although there are signs that it is important and, hopefully, this will stimulate further research. Empirical studies of pet birds are needed in order to ascertain whether direction or strength of visual lateralization is associated with level of stress and welfare in pet birds.

\section{Conclusions}

In general, welfare of birds is enhanced by dominance of the left hemisphere in most circumstances, mostly because it can inhibit control by the right hemisphere and, therefore, suppress the expression of aggression and fear. This has been argued also for a range of vertebrate species [68,112]. Reduced lateralization, associated with reduced interhemispheric connections, has been associated with a number of negative psychological states in humans, such as post-traumatic stress disorder (e.g., [113-116]) and stress is associated with changes in lateralization in humans [117]. In non-human vertebrate species, living in conditions of poor welfare is associated with different degrees of lateralization [118,119]. Availability of sufficient space is of paramount importance for enrichment, and hence good welfare, and it can influence lateralization [120]. As we have discussed, being visually Lateralized also affects the bird's ability to make use of space and engage in a variety of normal behaviours that, under the circumstances of commercial production, might be classified as enriching behaviour. Thus far, very little research attention has been directed towards studying associations between lateralization and welfare of birds. It is, however, already clear that lateralization of some important visually guided behaviour in birds can be generated or strengthened by exposing the developing embryos to light. We are not, of course, suggesting light exposure of embryos as a panacea of all aspects of lateralization that might impinge on welfare, especially since its effects are confined to the visual modality [121] and it does not affect lateralization of all types of visually guided behaviour (e.g., eye-system differences in social recognition [122]). Nevertheless, exposure to light does have effects on early post-hatching behaviour that seem to be positive and could have long-term consequences beneficial to birds kept in flocks, as well as aiding them to deal with stressful situations. Further research is needed to ascertain whether this is the case.

Author Contributions: Writing—Original draft preparation, L.J.R.; Writing—Review and editing, G.K.

Funding: This research received no external funding.

Conflicts of Interest: The authors declare no conflict of interest.

\section{References}

1. Rogers, L.J.; Vallortigara, G.; Andrew, R.J. Divided Brains: The Biology and Behaviour of Brain Asymmetries; Cambridge University Press: Cambridge, UK, 2013. 
2. Rogers, L.J.; Vallortigara, G. When and why did brains break symmetry. Symmetry 2015, 7, $2181-2194$. [CrossRef]

3. Ocklenburg, S.; Güntürkün, O. The Lateralized Brain: The Neuroscience and Evolution of Hemispheric Asymmetries; Academic Press: London, UK, 2018.

4. Frasnelli, E.; Vallortigara, G.; Rogers, L.J. Left-right asymmetries of behaviour and nervous system in invertebrates. Neurosci. Biobehav. Rev. 2012, 36, 1273-1291. [CrossRef] [PubMed]

5. Rogers, L.J.; Vallortigara, G. From antenna to antenna: Lateral shift of olfactory memory recall by honeybees. PLoS ONE 2008, 3, e2340. [CrossRef] [PubMed]

6. Rogers, L.J.; Rigosi, E.; Frasnelli, E.; Vallortigara, G. A right antenna for social behaviour in honeybees. Sci. Rep. 2013, 3, 2045. [CrossRef] [PubMed]

7. Nottebohm, F. Neural lateralization of vocal control in a Passerine bird: I. Song. J. Exp. Zool. 1971, 177, 229-261. [CrossRef] [PubMed]

8. Nottebohm, F. Neural lateralization of vocal control in a Passerine bird: II. Sub-song, calls, and a theory of vocal learning. J. Exp. Zool. 1972, 179, 35-50. [CrossRef]

9. Nottebohm, F. Asymmetries in Neural Control of Vocalization in the Canary. In Lateralization of the Nervous System; Harnard, S., Doty, R.W., Goldstein, L., Jaynes, J., Krauthamer, G., Eds.; Academic Press: New York, NY, USA, 1977; pp. 23-44.

10. Phan, M.L.; Gergues, M.M.; Mahidadia, S.; Jimenez-Castillo, J.; Vicario, D.; Bieszczad, K.M. HDAC3 inhibitor RGFP966 modulates neural memory for vocal communication signals in a songbird model. Front. Syst. Neurosci. 2017, 11, 65. [CrossRef] [PubMed]

11. Prather, J.F.; Okanoya, K.; Bolhuis, J.J. Brains of birds and babies: Neural parallels between birdsong and speech acquisition. Neurosci. Biobehav. Rev. 2017, 81, 225-237. [CrossRef]

12. Rogers, L.J.; Anson, J.M. Lateralisation of function in the chicken fore-brain. Pharmacol. Biochem. Behav. 1979, 10, 679-686. [CrossRef]

13. Rogers, L.J. Light experience and asymmetry of brain function in chickens. Nature 1982, 297, $223-225$. [CrossRef]

14. Andrew, R.J.; Mench, J.; Rainey, C. Right-left asymmetry of response to visual stimuli in the domestic chick. In Analysis of Visual Behavior; Ingle, D.J., Goodale, M.A., Mansfield, R.J., Eds.; MIT Press: Cambridge, MA, USA, 1982; pp. 225-236.

15. Mench, J.; Andrew, R.J. Lateralisation of a food search task in the domestic chick. Behav. Neural. Biol. 1986, 46, 107-114. [CrossRef]

16. Rogers, L.J.; Zappia, J.V.; Bullock, S.P. Testosterone and eye-brain asymmetry for copulation in chickens. Experientia 1985, 41, 1447-1449. [CrossRef]

17. Vallortigara, G.; Cozzutti, C.; Tommasi, L.; Rogers, L.J. How birds use their eyes: Opposite left-right specialization for the lateral and frontal visual hemifield in the domestic chick. Curr. Biol. 2001, 11, 29-33. [CrossRef]

18. Vallortigara, G.; Andrew, R.J. Lateralization of response to change in a model partner by chicks. Anim. Behav. 1991, 41, 187-194. [CrossRef]

19. Vallortigara, G.; Andrew, R.J. Differential involvement of right and left hemisphere in individual recognition in the domestic chick. Behav. Proc. 1994, 33, 41-58. [CrossRef]

20. Daisley, J.N.; Mascalzoni, E.; Rosa-Salva, O.; Rugani, R.; Regolin, L. Lateralization of social cognition in the domestic chicken (Gallus gallus). Phil. Trans. R. Soc. B 2009, 364, 965e981. [CrossRef] [PubMed]

21. Daisley, J.N.; Vallortigara, G.; Regolin, L. Logic in an asymmetrical (social) brain: Transitive inference in the young domestic chick. Soc. Neurosci. 2010, 5, 309-319. [CrossRef]

22. Rosa-Salva, O.; Daisley, J.N.; Regolin, L.; Vallortigara, G. Lateralization of social learning in the domestic chick, Gallus gallus domesticus: learning to avoid. Anim. Behav. 2009, 78, 847-856. [CrossRef]

23. Dharmaretnam, M.; Rogers, L.J. Hemispheric specialization and dual processing in strongly versus weakly lateralized chicks. Behav. Brain Res. 2005, 162, 62-70. [CrossRef]

24. Rogers, L.J. Evolution of hemispheric specialisation: Advantages and disadvantages. Brain Lang. 2000, 73, 236-253. [CrossRef]

25. Rogers, L.J. The two hemispheres of the avian brain: their differing roles in perceptual processing and the expression of behaviour. J. Ornithol. 2012, 153, S61-S74. [CrossRef] 
26. Rugani, R.; Salva, O.R.; Regolin, L.; Vallortigara, G. Brain asymmetry modulates perception of biological motion in newborn chicks (Gallus gallus). Behav. Brain Res. 2015, 290, 1-7. [CrossRef] [PubMed]

27. Andrew, R.J.; Brennan, A. Sharply timed and lateralized events at the time of establishment of long term memory. Physiol. Behav. 1985, 34, 547-556. [CrossRef]

28. Andrew, R.J. The differential roles of right and left sides of the brain in memory formation. Behav. Brain Res. 1999, 98, 289-295. [CrossRef]

29. Rogers, L.J. Light input and the reversal of functional lateralization in the chicken brain. Behav. Brain Res. 1990, 38, 211-221. [CrossRef]

30. Güntürkün, O.; Kesch, S. Visual lateralization during feeding in pigeons. Behav. Neurosci. 1987, 101, $433-435$. [CrossRef] [PubMed]

31. Von Fersen, L.; Güntürkün, O. Visual memory lateralization in pigeons. Neuropsychologia 1990, $28,1-7$. [CrossRef]

32. Yamazaki, Y.; Aust, U.; Huber, L.; Hausmann, M.; Güntürkün, O. Lateralized cognition: asymmetrical and complementary strategies of pigeons during discrimination of the "human concept". Cognition 2007, 104, 315-344. [CrossRef]

33. Xiao, Q.; Güntürkün, O. Asymmetrical commissural control of the subdominant hemisphere in pigeons. Cell. Rep. 2018, 25, 1171-1180. [CrossRef]

34. Freund, N.; Valencia-Alfonso, C.E.; Kirsch, J.; Brodmann, K.; Manns, M.; Güntürkün, O. Asymmetric top-down modulation of ascending visual pathways in pigeons. Neurosychologia 2016, 83, 37-47. [CrossRef]

35. Diekamp, B.; Regolin, L.; Güntürkün, O.; Vallortigara, G. A left-sided visuospatial bias in birds. Curr. Biol. 2005, 15, R372-R373. [CrossRef] [PubMed]

36. Pollonara, E.; Guilford, T.; Rossi, M.; Bingman, V.P.; Gagliardo, A. Right hemisphere advantage in the development of route fidelity in homing pigeons. Anim. Behav. 2017, 123, 395-409. [CrossRef]

37. Tommasi, L.; Vallortigara, G. Encoding geometric and landmark information in the left and right hemispheres of the avian brain. Behav. Neurosci. 2001, 115, 602-613. [CrossRef] [PubMed]

38. Clayton, N.; Krebs, J.R. Memory for spatial and object specific cues in food-storing and non-storing birds. J. Comp. Physiol. A 1994, 174, 371-379. [CrossRef]

39. Alonso, Y. Lateralization of visual guided behavior during feeding in zebra finches (Taeniopygia guttata). Behav. Proc. 1998, 43, 257-263. [CrossRef]

40. Rogers, L.J.; Koboroff, A.; Kaplan, G. Lateral asymmetry of brain and behaviour in the zebra finch, Taeniopygia guttata. Symmetry 2018, 10, 679. [CrossRef]

41. Workman, L.; Andrew, R.J. Asymmetries of eye use in birds. Anim. Behav. 1986, 34, 1582-1584. [CrossRef]

42. Ten Cate, C.; Baauw, A.; Ballintijn, M.; Van der Horst, I. Lateralization of orientation in sexually active zebra finches: Eye use asymmetry of locomotion bias? Anim. Behav. 1990, 39, 992-994. [CrossRef]

43. George, I.; Hara, E.; Hessler, N.A. Behavioral and neural lateralization of vision in courtship singing of the zebra finch. J. Neurobiol. 2006, 66, 1164-1173. [CrossRef]

44. Templeton, J.J.; McCracken, B.G.; Sher, M.; Mountjoy, D.J. An eye for beauty: Lateralized visual stimulation of courtship behaviour and mate preferences in male zebra finches, Taeniopygia. guttata. Behav. Proc. 2014, 102, 33-39. [CrossRef]

45. Andrew, R.J.; Rogers, L.J. The Nature of Lateralization in Tetrapods. In Comparative Vertebrate Lateralization; Rogers, L.J., Andrew, R.J., Eds.; Cambridge University Press: New York, NY, USA, 2002; pp. 94-125.

46. Pryke, S.R.; Giffith, S.C. Red dominates black: agonistic signalling among head morphs in the colour polymorphic Gouldian finch. Proc. R. Soc. B 2005, 273, 949-957. [CrossRef] [PubMed]

47. Templeton, J.J.; Mountjoy, D.J.; Pryke, S.R.; Griffith, S.C. In the eye of the beholder: visual mate choice lateralization in a polymorphic songbird. Biol. Lett. 2012, 8, 924-927. [CrossRef] [PubMed]

48. Valenti, A.; Sovrano, V.A.; Zucca, P.; Vallortigara, G. Visual lateralisation in quails (Coturnix coturnix). Laterality 2003, 8, 67-78. [CrossRef]

49. Gülbetekin, E.; Güntürkün, O.; Dural, S.; çetinkaya, H. Asymmetry of visually guided sexual behaviour in adult Japanese quail (Coturnix japonica). Laterality 2007, 12, 321-331. [CrossRef] [PubMed]

50. Gülbetekin, E.; Güntürkün, O.; Dural, S.; çetinkaya, H. Visual asymmetries in Japanese quail (Coturnix japonica) retain a lifelong potential for plasticity. Behav. Neurosci. 2009, 123, 815-821. [CrossRef]

51. MacNeilage, P.; Rogers, L.J.; Vallortigara, G. Origins of the left and right brain. Sci. Am. 2009, 301, 60-67. [CrossRef] 
52. Franklin, W.E.; Lima, S.L. Laterality in avian vigilance: Do sparrows have a favourite eye? Anim. Behav. 2001, 62, 879-885. [CrossRef]

53. Rogers, L.J. Advantages and disadvantages of lateralization. In Comparative Vertebrate Lateralization; Rogers, L.J., Andrew, R.J., Eds.; Cambridge University Press: New York, NY, USA, 2002; pp. 126-153.

54. Ventolini, N.; Ferrero, E.A.; Sponza, S.; Della-Chiesa, A.; Vallortigara, G. Laterality in the wild: Preferential hemifield use during predatory and sexual behaviour in the black-winged stilt. Anim. Behav. 2005, 69, 1077-1084. [CrossRef]

55. Vallortigara, G.; Rogers, L.J.; Bisazza, A.; Lippolis, G.; Robins, A. Complementary right and left hemifield use for predatory and agonistic behaviour in toads. Neuroreport 1998, 9, 3341-3344. [CrossRef]

56. Kaplan, G. Audition and hemispheric specialization in songbirds and new evidence from Australian magpies. Symmetry 2017, 9, 99. [CrossRef]

57. Koboroff, A.; Kaplan, G.; Rogers, L.J. Hemispheric specialization in Australian magpies (Gymnorhina tibicen) shown as eye preferences during response to a predator. Brain. Res. Bull. 2008, 76, 304-306. [CrossRef] [PubMed]

58. Hoffman, A.M.; Robakiewicz, P.E.; Tuttle, E.M.; Rogers, L.J. Behavioural lateralization in the Australian magpie (Gymnorhina tibicen). Laterality 2006, 11, 110-121. [CrossRef] [PubMed]

59. Rogers, L.J.; Kaplan, G. An eye for a predator: Lateralization in Birds, with Particular Reference to the Australian Magpie. In Behavioral and Morphological Asymmetries in Vertebrates; Malashichev, Y.B., Deckel, A.W., Eds.; Landes Bioscience Publishing: Austin, TX, USA, 2006; pp. 47-57.

60. Kaplan, G.; Rogers, L.J. Stability of referential signalling across time and locations: Testing alarm calls of Australian magpies (Gymnorhina tibicen) in urban and rural Australia and in Fiji. PeerJ 2013, 1, e112. [CrossRef] [PubMed]

61. Beauchamp, G. Foraging success in a wild species of bird varies depending on which eye is used for anti-predator vigilance. Laterality 2013, 18, 194-202. [CrossRef] [PubMed]

62. Randler, C. Eye preference for vigilance during feeding in coot, Fulica atra, and geese, Anser anser and Anser cygnoides. Laterality 2005, 10, 535-543. [PubMed]

63. Grace, J.; Craig, D.P. The development and lateralization of prey delivery in a bill load-holding bird. Anim. Behav. 2008, 75, 2005-2011. [CrossRef]

64. Stor, T.; Rebstock, G.A.; Borboroglu, P.G.; Boesma, P.D. Lateralization (handedness) in Magellanic penguins. PeerJ 2019, 7, 6936. [CrossRef]

65. Robins, A.; Lippolis, G.; Bisazza, A.; Vallortigara, G.; Rogers, L.J. Lateralization of agonistic responses and hind-limb use in toads. Anim. Behav. 1998, 56, 875-881. [CrossRef]

66. Austin, N.A.; Rogers, L.J. Limb preferences and lateralization of aggression, reactivity and vigilance in feral horses (Equus caballus). Anim. Behav. 2012, 83, 239-247. [CrossRef]

67. Krakauer, A.H.; Blundell, M.A.; Scanlan, T.N.; Weschsler, M.S.; McCloskey, E.A.; Yu, J.H.; Patricelli, G.L. Successfully mating male sage-grouse show greater laterality in courtship and aggressive interactions. Anim. Behav. 2016, 111, 261-267. [CrossRef]

68. Leliveld, L.M.C.; Langbein, J.; Puppe, B. The emergence of emotional lateralization: Evidence in non-human vertebrates and implications for farm animals. Appl. Anim. Behav. Sci. 2013, 145, 1-14. [CrossRef]

69. Scarf, H.M.; Stenstrom, K.; Dainson, M.; Benson, T.; Fernandez-Juricic, E.; Hauber, M.E. Mimicry-dependent lateralization of visual inspection of foreign eggs by American robins. Biol. Lett. 2019, 15. [CrossRef]

70. Vallortigara, G.; Rogers, L.J. Survival with an asymmetrical brain: advantages and disadvantages of cerebral lateralization. Behav. Brain. Sci. 2005, 28, 575-589. [CrossRef] [PubMed]

71. Anfora, G.; Frasnelli, E.; Maccangani, B. Behavioural and electrophysiological lateralisation in a social (Apis mellifora) but not a non-social (Osmia cornuta) species of bee. Behav. Brain. Res. 2010, 206, 236-239. [CrossRef] [PubMed]

72. Rogers, L.J.; Frasnelli, E.; Versace, E. Lateralized antennal control of aggression and sex differences in red mason bees, Osmia bicornis. Sci. Rep. 2016, 6, 29411. [CrossRef] [PubMed]

73. Güntürkün, O.; Diekamp, B.; Manns, M.; Nottlemann, F.; Prior, H.; Schwarz, A.; Skiba, M. Asymmetry pays: Visual lateralization improves discrimination success in pigeons. Curr. Biol. 2000, 10, 1079-1081.

74. Magat, M.; Brown, C. Laterality enhances cognition in Australian parrots. Proc. R. Soc. Lond. B 2009, 276, 4155-4162. [CrossRef] 
75. Rogers, L.J.; Zucca, P.; Vallortigara, G. Advantage of having a lateralized brain. Proc. R. Soc. Lond. 2004, 271, S420-S422. [CrossRef]

76. Skiba, M.; Diekamp, B.; Güntürkün, O. Embryonic light stimulation induces different asymmetries in visuoperceptual and visuomotor pathways of pigeons. Behav. Brain Res. 2002, 134, 149-156. [CrossRef]

77. Rogers, L.J.; Sink, H.S. Transient asymmetry in the projections of the rostral thalamus to the visual hyperstriatum of the chicken, and reversal of its direction by light exposure. Exp. Brain Res. 1988, 70, 378-384. [CrossRef]

78. Güntürkün, O.; Hellmann, B.; Melsbach, G.; Prior, H. Asymmetries of representation in the visual system of pigeons. Neuroreport 1998, 9, 4127-4130. [CrossRef] [PubMed]

79. Manns, M.; Stöckens, F. Functional and structural comparison of visual lateralization in birds-similar but still different. Front. Psychol. 2014, 5, 206. [CrossRef] [PubMed]

80. Manns, M.; Römling, J. The impact of asymmetrical light input on cerebral hemispheric specialization and interhemispheric cooperation. Nat. Commun. 2012, 3, 696. [CrossRef] [PubMed]

81. Letzner, S.; Patzke, N.; Verhaal, J.; Manns, M. Shaping a lateralized brain: asymmetrical light experience modulates access to visual interhemispheric information in pigeons. Sci. Rep. 2014, 4, 4253. [CrossRef] [PubMed]

82. Letzner, S.; Güntürkün, O.; Lor, S.; Pawlik, P.J.; Manns, M. Visuospatial attention in the lateralised brain of pigeons-a matter of ontogenetic light experiences. Sci. Rep. 2017, 7, 15547. [CrossRef] [PubMed]

83. Güntürkün, O.; Ocklenburg, S. Ontogenesis of lateralization. Neuron 2017, 94, 249-263. [CrossRef] [PubMed]

84. Chiandetti, C.; Lemaire, B.; Versace, E.; Vallortigara, G. Early-and late-light embryonic stimulation modulates similarly chicks' ability to filter out distractors. Symmetry 2017, 9, 84. [CrossRef]

85. Chiandetti, C.; Galliussi, J.; Andrew, R.J.; Vallortigara, G. Early-light embryonic stimulation suggests a second route, via gene activation, to cerebral lateralization in vertebrates. Sci. Rep. 2013, 3, 2701. [CrossRef]

86. Zappia, J.V.; Rogers, L.J. Light experience during development affects asymmetry of fore-brain function in chickens. Dev. Brain Res. 1983, 11, 93-106. [CrossRef]

87. Chiandetti, C.; Vallortigara, G. Distinct effect of early and later embryonic light-stimulation on chicks' lateralization. Neuroscience 2019, 414, 1-7. [CrossRef]

88. Rogers, L.J.; Workman, L. Light exposure during incubation affects competitive behaviour in domestic chicks. Appl. Anim. Behav. Sci. 1989, 23, 187-198. [CrossRef]

89. Wichman, A.; Freire, R.; Rogers, L.J. Light exposure during incubation and social and vigilance behaviour in domestic chicks. Laterality 2009, 14, 381-394. [CrossRef] [PubMed]

90. Archer, G.S.; Mench, J.A. Natural incubation patterns and the effects of exposing eggs to light at various times during incubation on post-hatch fear and stress responses in broiler (meat) chickens. Appl. Anim. Behav. Sci. 2014, 152, 44-51. [CrossRef]

91. Archer, G.S.; Mench, J.A. Exposing avian embryos to light affects post-hatch antipredator fear responses. Appl. Anim. Behav. Sci. 2017, 186, 80-84. [CrossRef]

92. Riedstra, B.; Groothuis, T.G.G. Prenatal light exposure affects early feather pecking behaviour in the domestic chick. Anim. Behav. 2004, 67, 1037-1042. [CrossRef]

93. Archer, G.S.; Shivaprasad, H.L.; Mench, J.A. Effect of providing light during incubation on the health, productivity and behaviour of broiler chickens. Poult. Sci. 2009, 88, 29-37. [CrossRef] [PubMed]

94. Rogers, L.J.; Ehrlich, D. Asymmetry in the chicken forebrain during development and a possible involvement of the supraoptic decussation. Neurosci. Lett. 1983, 37, 123-127. [CrossRef]

95. Workman, L.; Andrew, R.J. Simultaneous changes in behaviour and in lateralization during development of male and female domestic chicks. Anim. Behav. 1989, 38, 596-605. [CrossRef]

96. Freire, R.; Rogers, L.J. Experience during a period of right hemispheric dominance alters attention to spatial information in the domestic chick. Anim. Behav. 2007, 74, 413-418. [CrossRef]

97. Wichman, A.; Rogers, L.J.; Freire, R. Visual lateralization and development of spatial and social spacing behaviour of chicks (Gallus gallus domesticus). Behav. Proc. 2009, 81, 14-19. [CrossRef]

98. Schwabl, H. Developmental changes and among-sibling variation of corticosterone levels in altricial avian species. Gen. Comp. Endocrin. 1999, 116, 403-408. [CrossRef] [PubMed]

99. Hayward, L.S.; Wingfield, J.C. Maternal corticosterone is transferred to avian yolk and may alter offspring growth and adult phenotype. Gen. Comp. Endocrinol. 2004, 135, 365-371. [CrossRef] [PubMed] 
100. Elf, P.K.; Fivizzani, A.J. Changes in steroid levels in yolks of the leghorn chicken, Gallus domesticus, during embryonic development. J. Exp. Zool. 2002, 293, 594-600. [CrossRef] [PubMed]

101. Rogers, L.J.; Deng, C. Corticosterone treatment of the chick embryo affects light-stimulated development of the thalamofugal visual pathway. Behav. Brain Res. 2005, 159, 63-71. [CrossRef] [PubMed]

102. Freire, R.; van Dort, S.; Rogers, L.J. Pre-and post-hatching effects of corticosterone treatment on behavior of the domestic chick. Horm. Behav. 2006, 49, 157-165. [CrossRef] [PubMed]

103. Henriksen, R.; Rettenbacher, S.; Groothuis, T.G.G. Prenatal stress in birds: Pathways, effects, function and perspectives. Neurosci. Biobehav. Rev. 2011, 35, 1484-1501. [CrossRef] [PubMed]

104. Butler, S.R.; Templeton, J.J.; Fernández-Juricic, E. How do birds look at their world? A novel avian visual fixation strategy. Behav. Ecol. Sociobiol. 2018, 72, 38. [CrossRef]

105. Moore, B.A.; Tyrrell, L.P.; Pita, D.; Bininda-Edmonds, O.R.P.; Fernández-Juricic, E. Does retinal configuration make the head and eyes of foveate birds move? Sci. Rep. 2017, 7, 38406. [CrossRef] [PubMed]

106. Dawkins, M. What are birds looking at? Head movements and eye use in chickens. Anim. Behav. 2002, 63, 991-998. [CrossRef]

107. Rogers, L.J.; Andrew, R.J. Frontal and lateral visual field use by chicks after treatment of testosterone. Anim. Behav. 1989, 38, 394-405. [CrossRef]

108. Harris, L.J. Footedness in parrots: three centuries of research, theory, and mere surmise. Canad. J. Psychol. 1989, 43, 369-396. [CrossRef] [PubMed]

109. Rogers, L.J. Lateralisation in the avian brain. Bird. Behav. 1980, 2, 1-12.

110. Brown, C.; Magat, M. Cerebral lateralization determines hand preferences in Australian parrots. Biol. Lett. 2011, 7, 496-498. [CrossRef] [PubMed]

111. Snyder, P.J.; Harris, L.J. Lexicon size and its relation to foot preference in the African Grey parrot (Psittacus erithacus). Neuropsychologia 1997, 35, 919-926. [CrossRef]

112. Rogers, L.J. Cognition and animal welfare. Wiley Interdiscip. Rev: Cogn. Sci. 2010, 1, 439-445. [CrossRef] [PubMed]

113. Saltzman, K.M.; Weems, C.F.; Reiss, A.L.; Carrión, V.G. Mixed lateral preference in posttraumatic stress disorder. J. Nerv. Ment. Dis. 2006, 194, 142-144. [CrossRef] [PubMed]

114. Spivak, B.; Segal, M.; Mester, R.; Weizman, A. Lateral preference in post-traumatic stress disorder. Psychol. Med. 1998, 28, 229-232. [CrossRef]

115. Mutluer, T.; Sar, V.; Kose-Demiray, C.; Arslan, H.; Tamer, S.; Inal, S.; Kacar, A.S. Lateralization of neurobiological response in adolescents with post-traumatic stress disorder related to severe childhood sexual abuse: the Tri-modal Reaction (T-MR) model of protection. J. Trauma. Dissoc. 2018, 19, 108-125. [CrossRef]

116. Ritov, G.; Barnetz, Z. PTSD and Lateral Preference: Overview of the Relationship between Distress Symptoms and Handedness. In Comprehensive Guide to Post-Traumatic Stress Disorders; Martin, C., Preedy, V., Patel, V., Eds.; Springer, Cham: Basel, Switzerland, 2016; pp. 435-453.

117. Ocklenburg, S.; Korte, S.M.; Peterburs, J.; Wolf, O.T.; Güntürkün, O. Stress and Laterality-the comparative perspective. Physiol. Behav. 2016, 164, 321-329. [CrossRef]

118. Demirbas, Y.S.; Isparta, S.; Ozturk, H.; Safak, E.; Emre, B.; Piskin, I.; Kaya, U.; Sagmanligil, V.; Akgul, B.; Da Graca Pereira, G. Functional cerebral asymmetry in dogs living under different environmental conditions. Behav. Proc. 2019, 165, 4-8. [CrossRef]

119. Fernández-Lázaro, G.; Latorre, R.; Alonso-García, E.; Núnez, I.B. Nonhuman primate welfare: Can there be a relationship between personality, lateralization and physiological indicators? Behav. Proc. 2019, 166, 103897. [CrossRef] [PubMed]

120. Zucca, P.; Cerri, F.; Carluccio, A.; Baciadonna, L. Space availability influence laterality in donkeys (Equus asinus). Behav. Proc. 2011, 88, 63-66. [CrossRef] [PubMed] 
121. Rogers, L.J.; Andrew, R.J.; Burne, T.H.J. Light exposure of the embryo and development of behavioural lateralisation in chicks: I. Olfactory responses. Behav. Brain Res. 1998, 97, 195-200. [CrossRef]

122. Deng, C.; Rogers, L.J. Social recognition and approach in the chick: Lateralization and effect of visual experience. Anim. Behav. 2002, 63, 697-706. [CrossRef]

(C) 2019 by the authors. Licensee MDPI, Basel, Switzerland. This article is an open access article distributed under the terms and conditions of the Creative Commons Attribution (CC BY) license (http://creativecommons.org/licenses/by/4.0/). 